\title{
Influence of the SARS-CoV-2 Outbreak on the Uptake of a Popular Smoking Cessation App in UK Smokers: Interrupted Time Series Analysis
}

Olga Perski ${ }^{1}$, PhD; Aleksandra Herbec ${ }^{1,2}, \mathrm{PhD}$; Lion Shahab ${ }^{1}$, PhD; Jamie Brown ${ }^{1}, \mathrm{PhD}$

${ }^{1}$ Department of Behavioural Science and Health, University College London, London, United Kingdom

${ }^{2}$ Department of Clinical, Educational and Health Psychology, University College London, London, United Kingdom

Corresponding Author:

Olga Perski, PhD

Department of Behavioural Science and Health

University College London

1-19 Torrington Place

London, WC1E 7HB

United Kingdom

Phone: 4402076791258

Email: olga.perski@ucl.ac.uk

\section{Abstract}

Background: The severe acute respiratory syndrome coronavirus 2 (SARS-CoV-2) outbreak may motivate smokers to attempt to stop in greater numbers. However, given the temporary closure of UK stop smoking services and vape shops, smokers attempting to quit may instead seek out mobile health support, such as smartphone apps.

Objective: We examined, using an interrupted time series approach, whether the SARS-CoV-2 outbreak has been associated with a step change or increasing trend in UK downloads of an otherwise popular smoking cessation app, Smoke Free.

Methods: Data were from daily and nondaily adult smokers in the United Kingdom who had downloaded the Smoke Free app between January 1, 2020, and March 31, 2020 (primary analysis), and January 1, 2019, and March 31, 2020 (secondary analysis). The outcome variable was the number of downloads aggregated at the 12-hourly (primary analysis) or daily level (secondary analysis). The explanatory variable was the start of the SARS-CoV-2 outbreak, operationalized as March 1, 2020 (primary analysis), and January 15, 2020 (secondary analysis). Generalized additive mixed models adjusted for relevant covariates were fitted.

Results: Data were collected on 45,105 (primary analysis) and 119,881 (secondary analysis) users. In both analyses, there was no evidence for a step change or increasing trend in downloads attributable to the start of the SARS-CoV-2 outbreak. Calculation of Bayes factors (BFs) indicated that the data for the primary analysis favored the null hypothesis compared with large associations (for level, $\mathrm{BF}=0.25$; for slope, $\mathrm{BF}=0.26$ ) but were insensitive to the detection of small associations (for level, $\mathrm{BF}=0.78$; for slope, $\mathrm{BF}=1.35)$.

Conclusions: In the United Kingdom, between January 1, 2020, and March 31, 2020, and between January 1, 2019, and March 31,2020 , there was no evidence that the SARS-CoV-2 outbreak has been associated with a large step change or increasing trend in downloads of a popular smoking cessation app. Findings on the association of the SARS-CoV-2 outbreak with a small step change or increasing trend were inconclusive.

(JMIR Mhealth Uhealth 2020;8(6):e19494) doi: 10.2196/19494

\section{KEYWORDS}

SARS-CoV-2; COVID-19; smoking cessation; mobile health; smartphone app; time series analysis; smoking; public health; app

\section{Introduction}

The global outbreak of severe acute respiratory syndrome coronavirus 2 (SARS-CoV-2), which causes the coronavirus disease (COVID-19) [1], was imported into the United Kingdom in January 2020 [2]. Community transmission has subsequently been established [3]. The growing spread of SARS-CoV-2 has been accompanied by a series of government announcements 
of escalating social distancing policies and legislation. On March 8, 2020, prime minister Boris Johnson unveiled the UK Coronavirus Action Plan [4], which was followed by government advice to practice social distancing on March 16 and behavioral restrictions enforceable by law on March 23, 2020 .

Definitive evidence on whether current smokers are at increased risk of disease, morbidity, and mortality from COVID-19 are not yet available. However, researchers and clinicians have emphasized biological (eg, reduced respiratory immune defense) and behavioral (eg, repetitive hand-to-mouth movements) factors that may mean that smokers are at an increased risk of contracting SARS-CoV-2 [5-7], and early evidence indicates that hospitalized smokers may be more likely to experience complications and mortality from COVID-19 compared with nonsmokers [8,9]. UK public health messaging focused on advice to stop smoking has been limited. On March 20, 2020, the charitable organization Action on Smoking and Health launched an online stop smoking campaign labelled "Today Is The Day" [10] with an accompanying hashtag, \#QuitForCovid (see Table 1 for a timeline of key UK events related to smoking and COVID-19). On April 3, 2020, Public Health England released a news story headlined "Smokers at greater risk of severe respiratory disease from COVID-19" [11], which generated substantial coverage [12,13].

Table 1. Timeline of key UK events in 2020 related to smoking and COVID-19, including government policies and legislation [14].

\begin{tabular}{|c|c|}
\hline Date & Key event \\
\hline January 31 & First two cases reported in the United Kingdom \\
\hline February 7 & $\begin{array}{l}\text { Primary care guidance updated to state that the virus is most likely to be seen in travelers returning from China, Hong Kong, } \\
\text { Japan, Macau, Malaysia, Republic of Korea, Singapore, Taiwan, or Thailand }\end{array}$ \\
\hline February 21 & At least 17 temporary $\mathrm{GP}^{\mathrm{a}}$ closures occur \\
\hline March 2 & GP practice closures continue \\
\hline March 6 & First UK patient dies from COVID-19 \\
\hline March 8 & Prime Minister Boris Johnson unveils the Coronavirus Action Plan \\
\hline March 11 & World Health Organization declares the severe acute respiratory syndrome coronavirus 2 outbreak a pandemic \\
\hline March 12 & UK COVID-19 risk level raised from moderate to high \\
\hline March 16 & $\begin{array}{l}\text { UK government advises on social distancing (eg, avoiding nonessential travel and contact with others); pregnant women, adults } \\
70 \text { years or older, and individuals with health conditions are urged to self-isolate }\end{array}$ \\
\hline March 18 & $\begin{array}{l}\text { UK government announces that schools will close to most students, with children of key workers and vulnerable children still } \\
\text { able to attend }\end{array}$ \\
\hline March 20 & $\begin{array}{l}\text { Restaurants, pubs, clubs, and indoor sport and leisure centers ordered to close; Action on Smoking and Health launches the stop } \\
\text { smoking campaign "Today Is The Day" and \#QuitForCovid }\end{array}$ \\
\hline March 23 & UK government announces restrictions made on freedom of movement, enforceable by law \\
\hline April 3 & $\begin{array}{l}\text { Public Health England releases a news story emphasizing the increased risk of severe respiratory disease due to COVID-19 in } \\
\text { smokers }\end{array}$ \\
\hline
\end{tabular}

${ }^{\mathrm{a}} \mathrm{GP}$ : general practice.

${ }^{\mathrm{b}}$ COVID-19: coronavirus disease.

Options for UK smokers interested in quitting usually include specialist stop smoking services and vape shops. However, the introduction of social distancing policies and behavioral restrictions enforceable by law mean that the vast majority of services and shops have temporarily closed. At the same time, it is plausible that the SARS-CoV-2 outbreak has acted as a "teachable moment," motivating smokers to attempt to stop in greater numbers than would otherwise be observed for this time of the year. Given these temporary closures of stop smoking services and vape shops, smokers attempting to quit during the SARS-CoV-2 outbreak may have to seek out digital support, such as websites and smartphone apps. If so, it would be important for public health bodies to put resources toward ramping up access to high-quality, evidence-informed digital support.
One way of assessing whether the recent SARS-CoV-2 outbreak has been accompanied by a surge in smokers accessing digital support is to use an interrupted time series approach to examine whether there has been a step change or increasing trend in downloads of an otherwise popular smoking cessation app. The Smoke Free app, designed for English speakers, includes behavior change techniques that can improve the chances of quitting and shows early evidence of effectiveness [15]. The app is live on the Apple and Google Play stores and has a large user base with $>1$ million global downloads per annum. The app exists as a free version with a set of core features and a paid ("pro") version with additional content.

This study used an interrupted time series approach to assess whether the SARS-CoV-2 outbreak up to the end of March 2020 
(ie, a hypothesized "teachable moment") has been accompanied by an increase in UK downloads of the free and "pro" versions of the Smoke Free app (henceforth referred to as the Smoke Free app). Two different starting points for the outbreak were used. First, we assessed whether there has been a step change or increasing trend (linear or nonlinear) in downloads during a period of government announcements of escalating social distancing policies and legislation, with March 1, 2020, as the stipulated starting point (see Table 1; a series of government announcements occurred throughout March 2020). Second, we assessed whether there has been an increasing trend (linear or nonlinear) in downloads over the course of the SARS-CoV-2 outbreak so far, compared with the preceding 12 months, with January 15,2020 , as the stipulated starting point. The middle of January 2020 was selected as a starting point to reduce confounding by the regularly observed annual spike in downloads from late December to mid-January.

Specifically, we aimed to address the following research questions:

1. Over a 3-month time series (ie, January 1, 2020, to March $31,2020)$, has a period of government announcements of escalating social distancing policies and legislation (ie, March 1, 2020, to March 31, 2020) been accompanied by a step change or increasing trend in UK downloads of the Smoke Free app?

2. Over a 15-month time series (ie, January 1, 2019, to March 31, 2020), has the SARS-CoV-2 outbreak thus far (ie, January 15, 2020, to March 31, 2020) been accompanied by an increasing trend in UK downloads of the Smoke Free app?

\section{Methods}

\section{Study Design}

This was a natural experiment without active recruitment. The study protocol and analysis plan were preregistered on the Open Science Framework [16]. The study involved the analysis of anonymized app data at the aggregate level and fell within the scope of "The optimisation and implementation of interventions to change behaviours related to health and the environment," approved by University College London's Research Ethics Committee (Project ID: CEHP/2020/579). Users provide consent for their data to be used in research by virtue of downloading the app and agreeing to the terms and conditions.

\section{Study Setting and Population}

To be included in the analytic sample, daily and nondaily smokers needed to be 18 years or older and have downloaded the Smoke Free app from a UK-based app store (ie, Google Play and Apple App Store) during the respective study periods.

\section{Measures}

\section{Outcomes}

For the primary analysis, the outcome of interest was the number of UK Smoke Free app downloads aggregated at the 12-hourly level. This temporal unit was selected to increase the number of observations in the postintervention period.
For the secondary analysis, the outcome of interest was the number of UK Smoke Free app downloads aggregated at the daily level.

\section{Exposures}

For the primary analysis, the 60-day period (or 120 observations) before the government announcements of escalating social distancing policies and legislation was coded as 0 , and the 31-day period (or 62 observations) containing the announcements was coded as 1 . The trend during the 31-day postintervention period from March 1, 2020, to March 31, 2020, (or 62 observations) was coded from 1-62.

For the secondary analysis, the 379-day period (or 379 observations) before the start of the SARS-CoV-2 outbreak was coded as 0 , and the trend over the 77-day period containing the outbreak from January 15, 2020, to March 31, 2020, (77 observations) was coded from 1-77.

\section{Covariates}

For the primary analysis, the time of day was included as a categorical covariate (midnight to 11:59 AM or "morning" vs noon to 11:59 PM or "evening"), and the day of the week was included as a cyclic cubic spline to capture nonlinear, seasonal patterns in downloads.

For the secondary analysis, the month of the year and the day of the week were included as cyclic cubic splines to capture nonlinear, seasonal patterns in downloads. Two additional covariates were included. On December 19, 2019, a new expert feature, which involved the ability to communicate directly with stop smoking counsellors, was launched for "pro" users (ie, “expert feature launch"). On December 27, 2019, a promotional offer to purchase a separate version of the app called Smoke Free Plus in a range of Boots stores across the United Kingdom was announced (ie, "national advertising campaign"). The periods before and after the expert feature launch and the national advertising campaign were coded as 0 and 1 , respectively.

\section{Data Analysis}

The analyses were conducted in R v.3.6.3 ( $\mathrm{R}$ Foundation for Statistical Computing) using the $m g c v$ package.

For the primary analysis, an interrupted time series analysis (segmented regression) was conducted using a generalized additive mixed model (GAMM). GAMMs take account of seasonality through the fitting of seasonal smoothing terms [17]. First, data were assessed for overdispersion (ie, when the variance is greater than the mean). As there was evidence for overdispersion, a quasi-Poisson distribution was specified. Second, plots of the autocorrelation function and partial autocorrelation function were assessed to identify plausible values for the autoregressive (AR) and moving average (MA) terms. Third, a segmented regression model was fitted. Different models with plausible AR and MA terms were compared using the Akaike information criterion (AIC), with smaller values indicating better model fit. The final segmented regression model included terms for a secular trend (denoting the number of observations in the entire study period), level (denoting the pre- and postintervention segments), slope (denoting the trend 
in the postintervention segment), time of day, and day of the week. The fit of models including linear, quadratic, and cubic trends for the postintervention segment was assessed using the AIC.

The same steps were repeated for the secondary analysis. The final model was selected in a similar way. As specified in the analytic plan, the model included terms for a secular trend, slope, month of the year, day of the week, the expert feature launch, and the national advertising campaign.

\section{Unplanned Sensitivity Analyses}

Prompted by inspection of the data and as a result of the review process, three unplanned sensitivity analyses (SAs) were conducted.

First, given uncertainties as to when the SARS-CoV-2 outbreak had started to affect smokers' lives, we modelled the starting point of the outbreak as approximately 15 days before (ie, February 15, 2020) and after (ie, March 15, 2020) the original starting point (ie, March 1, 2020). These SAs were considered exploratory (as opposed to hypothesis testing).

Second, SAs were conducted to examine whether observed nonsignificant associations for the primary analysis could best be characterized as evidence of no effect or whether the data were insensitive to distinguish the null from the alternative hypothesis [18]. Bayes factors (BFs) with the alternative hypotheses conservatively represented by a half-normal distribution were calculated using an online calculator [19]. With the alternative hypothesis represented by a half-normal distribution, the standard deviation of a distribution can be specified as an expected effect size, meaning that plausible values are represented between zero and twice the effect size, with smaller values being more likely. The expected effect sizes for the level (ie, step change) and slope (ie, the trend in the postintervention period) were set as follows: first, we imagined a large step change on the basis of a hypothetical scenario in which all smokers who would otherwise attempt to quit with electronic cigarettes (e-cigarettes) or stop smoking services (ie, $\sim 30 \%$ of the $1,890,000$ UK smokers who make a quit attempt each year [20] or 567,000 smokers), spread equally across the year (ie, 567,000/365 days=1553), would switch immediately to the Smoke Free app. With a base rate of $\sim 400$ Smoke Free downloads per day, this would equate to an incidence rate ratio (IRR) of 1953/400 (IRR=4.9). Second, we imagined a large slope on the basis of the 1553 additional smokers projected to switch at a given point in time (ie, the expected large step change) instead switching gradually (and uniformly) from e-cigarettes or stop smoking services to the Smoke Free app over a 1-month period (ie, an additional 52 smokers switching per day), thus equating to a large slope or an IRR of $452 / 400$ (IRR=1.13). Third, we imagined a small step change on the basis of a hypothetical scenario in which $5 \%$ of the 1,890,000 UK smokers who make a quit attempt each year with e-cigarettes or stop smoking services would switch immediately to the Smoke Free app (ie, 94,500/365=259). With a base rate of $\sim 400$ Smoke Free downloads per day, this would equate to an IRR of 659/400 (IRR=1.6). Fourth, we imagined a small slope on the basis of the 259 additional smokers projected to switch at a given point in time (ie, the expected small step change) instead switching gradually over a 1-month period (ie, 9 additional smokers switching per day), thus equating to an IRR of 409/400 ( $I R R=1.02$ ). $B F s ~ \geq 3$ can be interpreted as substantial evidence for the alternative hypothesis and against the null. $\mathrm{BFs} \leq 1 / 3$ can be interpreted as evidence for the null hypothesis. BFs between $1 / 3$ and 3 suggest that the data are insensitive to distinguish the alternative hypothesis from the null [18].

Third, with additional data becoming available, the primary and secondary analyses were topped up with data up to May 12, 2020. These SAs were considered exploratory.

\section{Results}

\section{Analyses}

Data were collected on 45,105 and 119,881 users, respectively. Figures 1 and 2 show graphs of the number of users downloading the app by month of the year for the respective analyses.

Table 2 shows the results for the best fitting segmented regression models for the primary and secondary analysis. In the primary analysis, there was no evidence for a step change or increasing trend in downloads attributable to the start of the SARS-CoV-2 outbreak on March 1, 2020. The rate of downloads was significantly greater in the evenings (IRR $=1.780,95 \% \mathrm{CI}$ $1.581-2.004, P<.001)$. In the secondary analysis, there was evidence for a very small but significant, linearly decreasing trend in downloads over the course of the entire study period (IRR=0.996, 95\% CI $0.994-0.998, P<.001)$. There was no evidence for an increasing trend in downloads attributable to the start of the SARS-CoV-2 outbreak on January 15, 2020. There was a substantial step change in downloads following the national advertising campaign (IRR=2.067, 95\% CI 1.387-3.079, $P<.001)$. 
Figure 1. The number of users downloading the Smoke Free app from January 1, 2020, to March 31, 2020. The dotted blue vertical line represents the stipulated starting point of the severe acute respiratory syndrome coronavirus 2 outbreak (ie, March 1, 2020). The solid red line represents the fitted values with a loess smoothing function applied and associated $95 \%$ CIs.

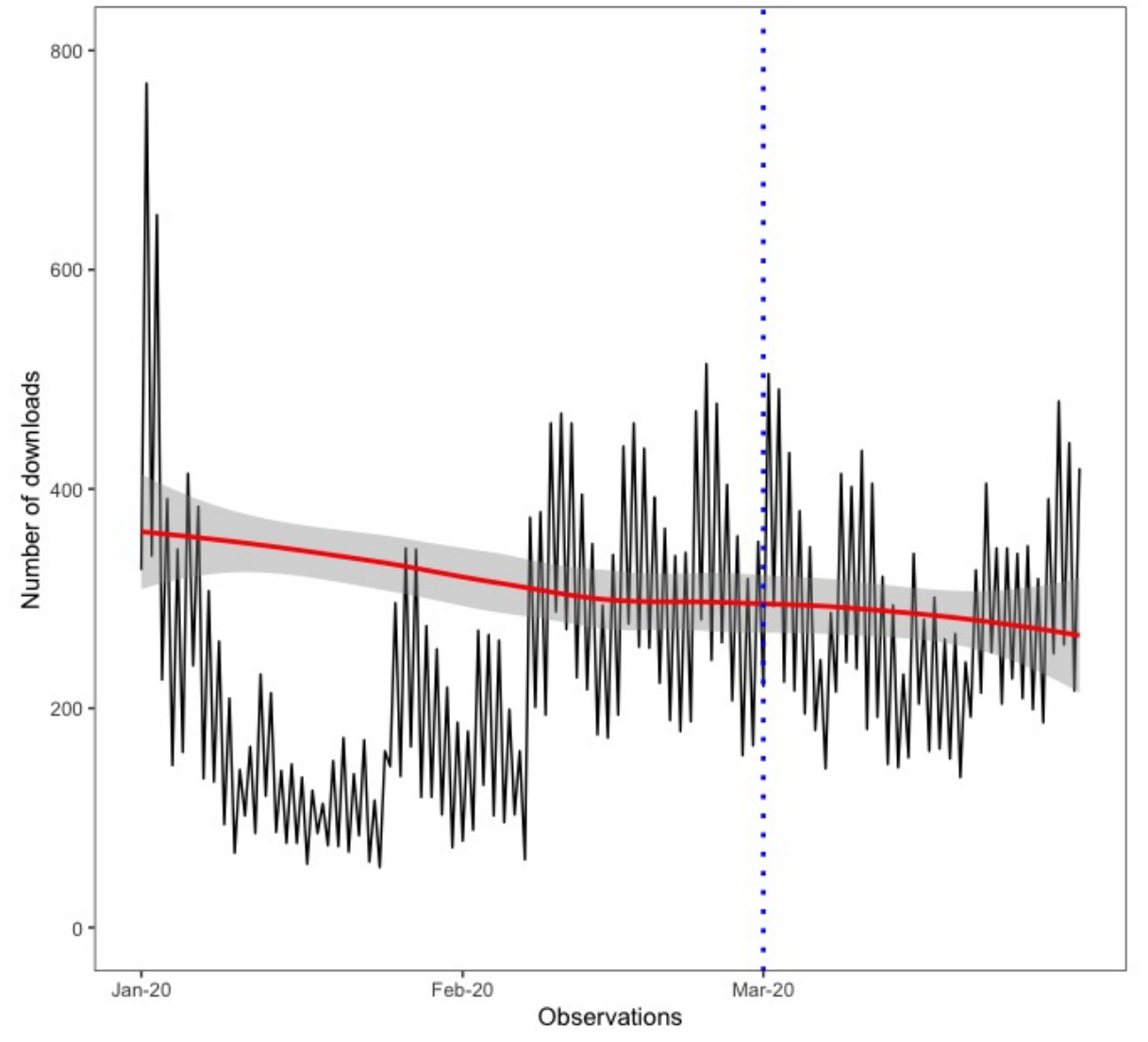

Figure 2. The number of users downloading the Smoke Free app from January 1, 2019, to March 31, 2020. The dotted blue vertical line represents the stipulated starting point of the severe acute respiratory syndrome coronavirus 2 outbreak (ie, January 15, 2020). The solid red line represents the fitted values with a loess smoothing function applied and associated 95\% CIs. For clarity, the y-axis was capped at 1300 downloads.

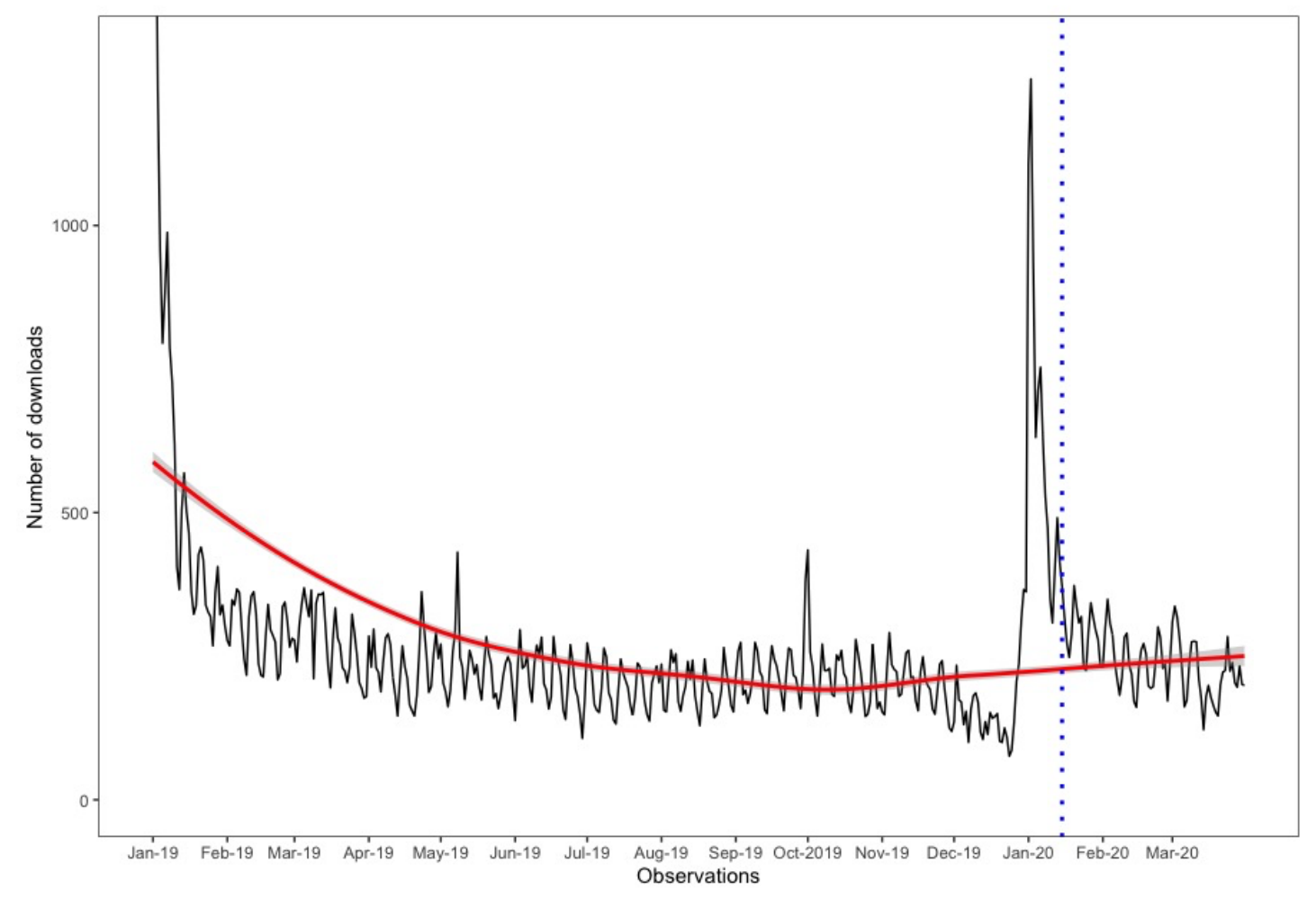


Table 2. Results from the best fitting model for each analysis.

\begin{tabular}{|c|c|c|c|c|c|}
\hline Analysis & $\operatorname{IRR}^{\mathrm{a}}(95 \% \mathrm{CI})$ & SE & $P$ value & $\begin{array}{l}\text { Bayes factor (small } \\
\text { expected effect) }\end{array}$ & $\begin{array}{l}\text { Bayes factor (large } \\
\text { expected effect) }\end{array}$ \\
\hline \multicolumn{6}{|l|}{ Primary analysis: January 1, 2020-March $31,2020^{b}$} \\
\hline Trend (January 1, 2020-March 31, 2020) & $0.998(0.994-1.002)$ & 0.002 & .23 & $N / A^{c}$ & N/A \\
\hline Level (March 1, 2020) & $1.142(0.916-1.423)$ & 0.112 & .24 & 0.78 & 0.25 \\
\hline Slope (March 1, 2020-March 31, 2020) & $0.999(0.988-1.010)$ & 0.006 & .85 & 1.35 & 0.26 \\
\hline Time of day ${ }^{\mathrm{d}}$ & $1.780(1.581-2.004)$ & 0.060 & $<.001$ & N/A & N/A \\
\hline \multicolumn{6}{|l|}{ Secondary analysis: January 1, 2019-March 31, 2020 } \\
\hline Trend (January 1, 2019-March 31, 2020) & $0.996(0.994-0.998)$ & 0.001 & $<.001$ & N/A & N/A \\
\hline Slope (January 15, 2020-March 31, 2020) & $0.976(0.908-1.049)$ & 0.037 & .51 & N/A & N/A \\
\hline Slope ${ }^{\wedge}$ & $1.001(0.998-1.003)$ & 0.001 & .52 & N/A & N/A \\
\hline Slope ${ }^{\wedge}$ & $1.000(1.000-1.000)$ & $<0.001$ & .54 & N/A & N/A \\
\hline Expert feature launch (December 19, 2019) ${ }^{\mathrm{f}}$ & $1.385(0.885-2.168)$ & 0.229 & .16 & N/A & N/A \\
\hline National advertising campaign (December 27, 2019) ${ }^{\mathrm{f}}$ & $2.067(1.387-3.079)$ & 0.203 & $<.001$ & N/A & N/A \\
\hline
\end{tabular}

${ }^{\mathrm{a}} \mathrm{IRR}$ : incidence rate ratio.

${ }^{\mathrm{b}}$ Adjusted for a second-order autoregressive term and day of the week.

${ }^{\mathrm{c}}$ Not applicable.

${ }^{\mathrm{d}}$ Referent=morning (vs evening).

${ }^{\mathrm{e}}$ Adjusted for a first-order autoregressive term, month of the year, and day of the week.

${ }^{\mathrm{f}}$ Modeled as a step change.

\section{Unplanned Sensitivity Analyses}

\section{Alternative Conceptualizations of the Outbreak}

When modeling the starting point of the outbreak as February 15, 2020, and March 15, 2020, there was no evidence for a step change or increasing trend in downloads attributable to the start of the SARS-CoV-2 outbreak (see Multimedia Appendix 1).

\section{Calculation of Bayes Factors}

The calculation of BFs indicated that the data for the primary analysis favored the null hypothesis compared with large associations (for level, $\mathrm{BF}=0.25$; for slope, $\mathrm{BF}=0.26$ ) but were insensitive to detection of small associations (for level, $\mathrm{BF}=0.78$; for slope, $\mathrm{BF}=1.35$; see Table 2).

\section{Analyses With Additional Data}

In the SAs repeating the primary and secondary analyses with additional data up to May 12, 2020, there was no evidence for a step change or increasing trend in downloads attributable to the start of the SARS-CoV-2 outbreak (see Multimedia Appendix 1).

\section{Discussion}

\section{Principal Findings}

This study used an interrupted time series approach to examine the impact of the ongoing SARS-CoV-2 outbreak on the uptake of an otherwise popular smoking cessation app in UK smokers. Across two different time periods and using two different conceptualizations of the starting point of the outbreak, we found no evidence for a step change or increasing trend in the number of downloads of the popular Smoke Free app. Calculation of BFs indicated that the data favored the null compared with large associations but were insensitive to detection of small associations.

\section{Limitations}

First, the small number of observations since the start of the SARS-CoV-2 outbreak means that we likely had low statistical power to detect anything but large effects. Second, pinpointing the exact starting point of the outbreak was not straightforward, as it is unclear when UK smokers first became aware of or affected by the pandemic, hypothesized to act as triggers for additional quit attempts. This was partly mitigated by conducting two SAs, which also did not provide evidence for a step change or increasing trend in downloads. Third, given the current structure of the app's database, we were unable to distinguish between downloads of the free and "pro" versions of the Smoke Free app in our analyses. Although a tally is kept for free and "pro" downloads combined, the tally kept for "pro" accounts has been designed to track weekly subscriptions (with each user counted several times) as opposed to one-off downloads. It is plausible that a greater number of smokers who otherwise would have tried to stop using e-cigarettes or stop smoking services would now be more inclined to purchase the "pro" version of the app. Fourth, the Smoke Free app is only one of many available online stop smoking platforms in the United Kingdom. We did not capture traffic on other available apps or websites such as the NHS Smokefree website [21] and were, hence, unable to model any effect of the SARS-CoV-2 outbreak on interest in stop smoking support (digital or nondigital) more 
broadly. For example, although vape shops are temporarily closed, it is plausible that online sales of e-cigarettes have increased during the study period. Fifth, we did not take account of tobacco industry behavior in our models. There has also been legitimate scientific investigation into the possible links between smoking, nicotine, and SARS-CoV-2 infection and COVID-19 outcomes [22,23]. In the absence of clear evidence as to whether smokers are at increased or reduced risk, it is plausible that the tobacco industry has attempted to capitalize on this uncertainty by, for example, influencing media reports, which may in turn have influenced quitting behavior.

\section{Implications for Policy}

The lack of an uptick in downloads of a popular smoking cessation app during the SARS-CoV-2 outbreak thus far suggests that smokers may not be turning to available, evidence-informed digital support in greater numbers. Evidence from controlled studies and population-level surveys indicate that smoking cessation attempts involving pharmacological or behavioral support (including digital interventions) are substantially more likely to be successful compared with unassisted attempts [24-26]. In the absence of readily available alternatives due to social distancing measures, UK public health bodies should consider putting resources toward increasing awareness of available, evidence-informed mobile health support.

\section{Conclusions}

In the UK, between January 1, 2020, and March 31, 2020, and between January 1, 2019, and March 31, 2020, there was no evidence that the SARS-CoV-2 outbreak thus far has been associated with a large step change or increasing trend in downloads of a popular smoking cessation app. Findings on the association of the SARS-CoV-2 outbreak with a small step change or increasing trend were inconclusive.

\section{Acknowledgments}

OP and JB receive salary support from Cancer Research UK (C1417/A22962). JB, LS, AH, and OP are members of Shaping Public Health Policies to Reduce Inequalities and Harm, a UK Prevention Research Partnership Consortium (MR/S037519/1). UK Prevention Research Partnership is an initiative funded by the UK Research and Innovation Councils, the Department of Health and Social Care (England) and the UK devolved administrations, and leading health research charities.

\section{Authors' Contributions}

OP, AH, LS, and JB designed the study. OP conducted the statistical analyses and wrote the first draft of the manuscript. All authors have contributed to the final version of the manuscript and agree with its submission to JMIR.

\section{Conflicts of Interest}

OP and JB are unpaid members of the scientific advisory committee for the Smoke Free app. LS has received a research grant and honoraria for a talk and travel expenses from manufacturers of smoking cessation medications (Pfizer and Johnson \& Johnson). JB and AH have received unrestricted research funding from Pfizer to study smoking cessation.

\section{Multimedia Appendix 1}

Sensitivity analyses.

[DOCX File, 17 KB-Multimedia Appendix 1]

\section{References}

1. Li Q, Guan X, Wu P, Wang X, Zhou L, Tong Y, et al. Early transmission dynamics in Wuhan, China, of novel coronavirus-infected pneumonia. N Engl J Med 2020 Mar 26;382(13):1199-1207 [FREE Full text] [doi: 10.1056/NEJMoa2001316] [Medline: 31995857]

2. Ball T, Wace C, Smyth C, Brown D. The Times. 2020 Jan 31. Hunt for contacts of coronavirus-stricken pair in York URL: http://web.archive.org/web/20200415110133/https://www.thetimes.co.uk/article/

hunt-for-contacts-of-coronavirus-stricken-pair-in-york-dh363qf8k

3. Department of Health and Social Care. 2020 Jan 24. Number of coronavirus (COVID-19) cases and risk in the UK URL: http://web.archive.org/web/20200415110345/https://www.gov.uk/guidance/coronavirus-covid-19-information-for-the-public [accessed 2020-03-31]

4. Department of Health and Social Care. 2020 Mar 03. Coronavirus (COVID-19) action plan URL: https://www.gov.uk/ government/publications/coronavirus-action-plan

5. Cox S. BMJ Opinion. 2020 Mar 20. Risky smoking practices and the coronavirus: a deadly mix for our most vulnerable smokers URL: http://web.archive.org/web/20200415110539/https://blogs.bmj.com/bmj/2020/03/20/ sharon-cox-risky-smoking-practices-and-the-coronavirus-a-deadly-mix-for-our-most-vulnerable-smokers/

6. Simons D, Perski O, Brown J. BMJ Opinion. 2020 Mar 20. Covid-19: the role of smoking cessation during respiratory virus epidemics URL: http://web.archive.org/web/20200415110656/https://blogs.bmj.com/bmj/2020/03/20/ covid-19-the-role-of-smoking-cessation-during-respiratory-virus-epidemics/ 
7. World Health Organization. 2020. Tobacco and waterpipe use increases the risk of suffering from COVID-19 URL: http:/ /web.archive.org/web/20200415110836/http://www.emro.who.int/tfi/know-the-truth/ tobacco-and-waterpipe-users-are-at-increased-risk-of-covid-19-infection.html [accessed 2020-04-15]

8. Vardavas CI, Nikitara K. COVID-19 and smoking: a systematic review of the evidence. Tob Induc Dis 2020;18:20 [FREE Full text] [doi: 10.18332/tid/119324] [Medline: 32206052]

9. Alqahtani J, Oyelade T, Aldhahir A, Alghamdi S, Almehmadi M, Alqahtani A, et al. Prevalence, severity and mortality associated with COPD and smoking in patients with COVID-19: a rapid systematic review and meta-analysis. PLoS One 2020;15(5):e0233147 [FREE Full text] [doi: 10.1371/journal.pone.0233147] [Medline: 32392262]

10. Today is the Day. 2020. URL: http://web.archive.org/web/20200415104921/https://www.todayistheday.co.uk/ [accessed 2020-04-15]

11. Public Health England. 2020 Apr 03. Smokers at greater risk of severe respiratory disease from COVID-19 URL: https:/ /www.gov.uk/government/news/smokers-at-greater-risk-of-severe-respiratory-disease-from-covid-19

12. Sky News. 2020 Apr 06. Coronavirus: 1.3 billion smokers urged to quit to reduce COVID-19 risks URL: http://web. archive.org/web/20200415112258/https://news.sky.com/story/ coronavirus-1-3-billion-smokers-urged-to-quit-to-reduce-covid-19-risks-11969444

13. Chalmers V. Daily Mail. Coronavirus warning for smokers: Experts says addicts face a greater risk of complications - but Chinese studies suggest they may be LESS likely to end up in hospital in the first place URL: http://web.archive.org/web/ 20200415112443/https://www.dailymail.co.uk/news/article-8184751/

Coronavirus-warning-smokers-Public-Health-England-says-addicts-face-greater-risk-coronavirus.html

14. MIMS. 2020. Live updates: coronavirus (COVID-19) in the UK URL: http://web.archive.org/web/20200415104434/https:/ /www.mims.co.uk/live-updates-coronavirus-covid-19-uk/infections-and-infestations/article/1673649 [accessed 2020-04-15]

15. Crane D, Ubhi HK, Brown J, West R. Relative effectiveness of a full versus reduced version of the 'Smoke Free' mobile application for smoking cessation: an exploratory randomised controlled trial. F1000Res 2018;7:1524 [FREE Full text] [doi: 10.12688/f1000research.16148.2] [Medline: $\underline{30728950]}$

16. Open Science Framework. 2020 Apr 06. Impact of the SARS-CoV-2 outbreak on the uptake of digital cessation support in UK smokers: a time series analysis URL: https://osf.io/zan2s/

17. Beard E, Marsden J, Brown J, Tombor I, Stapleton J, Michie S, et al. Understanding and using time series analyses in addiction research. Addiction 2019 Oct;114(10):1866-1884. [doi: 10.1111/add.14643] [Medline: 31058392]

18. Dienes Z. Bayesian versus orthodox statistics: which side are you on? Perspect Psychol Sci 2011 May;6(3):274-290. [doi: 10.1177/1745691611406920] [Medline: 26168518]

19. Dienes Z. University of Sussex. Online calculator URL: http://www.lifesci.sussex.ac.uk/home/Zoltan_Dienes/inference/ Bayes.htm

20. Smoking in England. 2020. URL: http://web.archive.org/web/20200415164408/http://www.smokinginengland.info/ [accessed 2020-04-15]

21. NHS. 2020. Smokefree URL: http://web.archive.org/web/20200415105232/https://www.nhs.uk/smokefree [accessed 2020-04-15]

22. de Lusignan S, Dorward J, Correa A, Jones N, Akinyemi O, Amirthalingam G, et al. Risk factors for SARS-CoV-2 among patients in the Oxford Royal College of General Practitioners Research and Surveillance Centre primary care network: a cross-sectional study. Lancet Infect Dis 2020 May:a. [doi: 10.1016/s1473-3099(20)30371-6]

23. Farsalinos K, Niaura R, Le Houezec J, Barbouni A, Tsatsakis A, Kouretas D, et al. Editorial: nicotine and SARS-CoV-2: COVID-19 may be a disease of the nicotinic cholinergic system. Toxicol Rep 2020 Apr 30 [FREE Full text] [doi: 10.1016/j.toxrep.2020.04.012] [Medline: 32355638]

24. Jackson SE, McGowan JA, Ubhi HK, Proudfoot H, Shahab L, Brown J, et al. Modelling continuous abstinence rates over time from clinical trials of pharmacological interventions for smoking cessation. Addiction 2019 May;114(5):787-797 [FREE Full text] [doi: 10.1111/add.14549] [Medline: $\underline{\text { 30614586] }}$

25. Jackson SE, Kotz D, West R, Brown J. Moderators of real-world effectiveness of smoking cessation aids: a population study. Addiction 2019 Sep;114(9):1627-1638 [FREE Full text] [doi: 10.1111/add.14656] [Medline: $\underline{31117151]}$

26. Kasza KA, Hyland AJ, Borland R, McNeill AD, Bansal-Travers M, Fix BV, et al. Effectiveness of stop-smoking medications: findings from the International Tobacco Control (ITC) Four Country Survey. Addiction 2013 Jan;108(1):193-202 [FREE Full text] [doi: 10.1111/j.1360-0443.2012.04009.x] [Medline: 22891869]

\section{Abbreviations}

AIC: Akaike information criterion

AR: autoregressive

BF: Bayes factor

COVID-19: coronavirus disease

e-cigarettes: electronic cigarettes

GAMM: generalized additive mixed model 
IRR: incidence rate ratio

MA: moving average

SA: sensitivity analysis

SARS-CoV-2: severe acute respiratory syndrome coronavirus 2

Edited by $G$ Eysenbach; submitted 20.04.20; peer-reviewed by E Davies, $N$ Abdul Wahab; comments to author 11.05.20; revised version received 27.05.20; accepted 27.05.20; published 11.06.20

Please cite as:

Perski O, Herbeć A, Shahab L, Brown J

Influence of the SARS-CoV-2 Outbreak on the Uptake of a Popular Smoking Cessation App in UK Smokers: Interrupted Time Series Analysis

JMIR Mhealth Uhealth 2020;8(6):e19494

URL: http://mhealth.jmir.org/2020/6/e19494/

doi: $10.2196 / 19494$

PMID: $\underline{32463375}$

(C) Olga Perski, Aleksandra Herbeć, Lion Shahab, Jamie Brown. Originally published in JMIR mHealth and uHealth (http://mhealth.jmir.org), 11.06.2020. This is an open-access article distributed under the terms of the Creative Commons Attribution License (https://creativecommons.org/licenses/by/4.0/), which permits unrestricted use, distribution, and reproduction in any medium, provided the original work, first published in JMIR mHealth and uHealth, is properly cited. The complete bibliographic information, a link to the original publication on http://mhealth.jmir.org/, as well as this copyright and license information must be included. 